\title{
PROCESOS INTERTEXTUALES Y ADAPTACIONES MUSICALES PARA LAS AVENTURAS DE DON QUIJOTE
}

\author{
Mariano LAMBEA \\ CSIC
}

En el libreto del disco compacto Música en la ínsula Barataria el profesor José Carlos Mainer escribió lo siguiente: «Para el conocedor de los resortes retóricos de la literatura no hay duda. Todo cuanto se escribe (antes del romanticismo, y quizá también después) procede por rememoración y actualización de unos protocolos inevitables, de unos modelos aprendidos en otras escrituras más antiguas y prestigiosas». ${ }^{1}$

¿Podemos decir que la música vocal profana española de la Edad de Oro procede también por rememoración y actualización de músicas pretéritas? Es muy posible que así sea, aunque la musicología española no se ha preocupado de demostrarlo, al menos de momento; ni de elaborar, siquiera, un corpus de melodías mediante el cual podamos establecer las oportunas interrelaciones entre ellas. Los musicólogos sabemos, por los filólogos, que el método propiamente creativo utilizado por los poetas de aquel tiempo era la imitación compuesta, y que la originalidad sólo se alcanzaba a partir del conocimiento de la tradición. En consecuencia, todo constituía en una reelaboración de la tradición, en cuyo proceso se imponía la intertextualidad poética: esa comunicación de los textos entre sí en la que palabras, signos e imágenes remiten unos a otros en una cadena interminable, compleja y sumamente enriquecedora. De esta manera, la intertextualidad poético-musical nos permite en la actualidad una reconstrucción fidedigna de estas obras, así como una interpretación vocal e instrumental mucho más precisa en la transmisión del sentido del texto y en las propias relaciones interdisciplinarias que se generan entre música y poesía. ${ }^{2}$

Los musicólogos no podemos negar la inspiración personal del compositor en la elaboración de una melodía determinada, pero esa inspiración subyace en la psique del músico mediatizada por el entorno musical desde mucho tiempo antes de que aflore. Y esto lo sabemos perfectamente los

José Carlos Mainer, Música en la Ínsula Barataria. El Quijote: romances, canciones y danzas, Zaragoza, AragónLCD Prames, 2004, pág. 30 (CD dirigido por Eliseo Parra).

2 Estamos plenamente de acuerdo con las siguientes palabras de María Cruz García de Enterría, extraídas de su trabajo "Bailes, romances, villancicos: modos de reutilización de composiciones poético-musicales", en Música y Literatura en la Península Ibérica: 1660-1750, ed. María Antonia Virgili Blanquet, Germán Vega García-Luengos y Carmelo Caballero Fernández-Rufete, Valladolid, 1997, págs. 169-70: «[...] textos poético-musicales en los que las redes de la intertextualidad forman un tejido inextricable en la concreta lectura o audición, pero claramente separables en el análisis de los propios textos. En ellos las palabras añaden posibilidades de transformación al estar unidas en el canto a la música y, así, hay melodías que unimos a determinadas palabras pero que pueden utilizar cómodamente otras, textos literarios que se cantan sobre distintas melodías o, todavía más: composiciones poético-musicales que se elaboraron para un determinado contexto y que pasan a otro diferente, con lo cual la lectura/audición cambia a veces muy profundamente». 
musicólogos que, además, somos músicos, porque cuando estudiamos la música en nuestra juventud, en ese período tan importante y decisivo de nuestra formación, recibimos, sin darnos cuenta, los referentes melódicos transmitidos de generación en generación, que proceden del venero inagotable de música que conforma esa especie de coiné musical que siempre ha permanecido oculta desde tiempos pasados, pero que en el momento de componer una melodía surge de manera natural y espontánea. Al componer imitamos, recordamos, rememoramos, evocamos y, finalmente, actualizamos. Entonces es cuando, parodiando a Paul Auster, nos damos cuenta de que aquella melodía que vagaba por nuestra mente estaba destinada, de antemano, a aquel texto que la estaba esperando para sublimar y expresar libremente sus afectos y contenidos. Obviamente, estamos hablando de la música compuesta bajo los parámetros de la modalidad o de la tonalidad, es decir, de esos sistemas de codificación sonora que regulan las relaciones entre los intervalos musicales. Modos o tonos, intervalos, notas musicales y duración de las mismas conforman un universo cerrado. Hay un número determinado de todos estos elementos y sus relaciones pueden ser casi infinitas, pero a la postre siempre acaban resultándonos familiares. En el juego del ajedrez sucede lo mismo: hay un tablero, unas fichas, unas casillas y unos movimientos regulados por unas normas. Todo también numéricamente contabilizado. Las combinaciones pueden ser hasta casi infinitas, pero para un ajedrecista profesional acaban siendo conocidas. El ajedrecista procede como el músico: recuerda los movimientos de las fichas y los actualiza en cada partida. Puede ser genial, como el compositor también, ya que la actividad de ambos va dirigida a la búsqueda de la perfección: o la jugada impecable o la melodía bella, pero todo está controlado; ninguna ficha puede hacer un movimiento prohibido ni salirse del tablero, como ninguna nota musical puede discordar, ni ningún intervalo musical puede salirse del esquema general de la modalidad o tonalidad. Si esto sucediera, estaríamos hablando de otro juego y de otra música, en los cuales ni ajedrecista ni compositor tendrían memoria creadora.

Antes de entrar en el contenido de nuestra comunicación conviene aclarar desde un primer momento que un tema es estudiar la música en El Quijote y otro muy distinto es estudiar El Quijote en la música. Ambos temas, tratados hace ya varias décadas por estudiosos procedentes de diversos ámbitos, han sido puestos al día por Juan José Pastor Comín en su tesis doctoral Música y literatura: la senda retórica. Hacia una nueva consideración de la música en Cervantes, presentada en la Universidad de Castilla-La Mancha y defendida en el mes de septiembre de 2004. El Dr. Pastor Comín ha incluido parte de esta investigación en el espléndido disco compacto titulado Por ásperos caminos. Nueva música cervantina. ${ }^{3}$

Aclarado este punto, en el verano del 2004 nuestro colega y amigo, el musicólogo y productor musical Dr. Albert Recasens, nos encargó a la Dra. Lola Josa, profesora de literatura española de la Edad de Oro de la Universidad de Barcelona, y a mí la elaboración de un repertorio para un disco compacto conmemorativo del IV Centenario de la publicación de la primera parte de El Quijote y patrocinado por la Comunidad de Madrid. Al recibir el encargo planificamos la siguiente estrategia: tomaríamos determinados pasajes de la novela e incluiríamos después de cada uno de ellos un poema concreto con referencia al contenido del pasaje. Estos poemas podían estar ya incluidos en El Quijote o ser ajenos a él. Posteriormente, indagaríamos en las fuentes poético-musicales de la época cuáles de esos poemas se habían conservado con su música y cuáles no. Para los que no tuvieran música, habría que buscarles una que se adecuara y adaptara convenientemente a su contenido poético, practicándole el pertinente contrafactum, técnica, como se sabe, muy utilizada en la época. Con este trueque semántico entre músicas y poesías hemos conseguido atemperar la expresividad y encauzar la aprehensión del concepto poético y la memoria del referente melódico, posibilitando una simbiosis poético-musical que alcanza siempre las cotas más preciadas de refinamiento estético y valor artístico. Partiendo de una metodología interdisciplinaria, hemos

3 Juan José Pastor, Por ásperos caminos. Nueva música cervantina, Universidad de Castilla-La Mancha, 2005 (CD dirigido por Sergio Barcellona). 
retocado algunas poesías para introducir los nombres propios del argumento cervantino, de la misma manera que hemos modificado estructuras musicales y adaptado fragmentos y repeticiones a tal o cual verso. Por ello nuestro trabajo ha consistido en una recreación poético-musical para don Quijote. El resultado es el disco compacto titulado Entre aventuras y encantamientos. Música para don Quijote que contiene dieciséis composiciones: trece de carácter profano con texto en castellano, dos religiosas con texto en latín y una instrumental (la elección de estas tres últimas no ha sido competencia nuestra). ${ }^{4}$

A continuación ofrecemos una clasificación de los poemas elegidos para las trece obras profanas con otros datos de interés sobre los autores de los textos y sobre las músicas y las fuentes poético-musicales:

A) Fragmentos de romances antiguos incluidos por Cervantes en El Quijote.

- Pista 4. «Dónde estás, señora mía?» (Romance del Marqués de Mantua) Texto anónimo. Romancero General (1600)

Música anónima. Cancionero Musical de Turín (ca. 1600)

B) Fragmentos de poemas de otros autores incluidos por Cervantes en El Quijote.

- Pista 10. «¡Oh, más dura que mármol a mis quejas!»

Texto de Garcilaso de la Vega (Égloga, I)

Música de Pedro Guerrero. Cancionero Musical de la Casa de Medinaceli (ca. 1550)

C) Poemas anónimos y de otros autores no incluidos por Cervantes en El Quijote.

- Pista 1. "Caballero de aventuras".

Texto y música anónimos. Romances y letras de a tres voces (primeras décadas del siglo XVII).

- Pista 2. «Señora, después que os vi»

Texto y música anónimos. Cancionero Musical de Turín (ca. 1600)

- Pista 3. "Quien tanto veros desea"

Texto de Jorge Manrique (Poesía cancioneril castellana)

Música anónima. Libro de Tonos Humanos (1656)

- Pista 5. "Al villano se la dan»

Texto y música anónimos. Romances y letras de a tres voces (primeras décadas del siglo XVII)

- Pista 6. «Nunca mucho costó poco» (primera cuarteta)

Texto de Lope de Vega (Comedia homónima)

Música de Carlos Patiño. Libro de Tonos Humanos (1656)

- Pista 7. "Al tronco de un verde mirto"

Texto de Luis de Góngora (Romances) ${ }^{6}$

Música de Fray Gerónimo. Cancionero Musical de Coimbra-B (ca. 1630)

D) Poemas compuestos por el propio Cervantes.

- Pista 6. «iTate, tate, folloncicos!» (segunda cuarteta de «Nunca mucho costó poco» de Lope)

Quijote (II, 74)

Música anónima. Cancionero Poético-Musical Hispánico de Lisboa (principios del siglo XVII)

\footnotetext{
Lola Josa y Mariano Lambea, Entre aventuras y encantamientos. Música para don Quijote, Madrid, Comunidad de Madrid, Consejería de Cultura y Deportes, 2005 (CD dirigido por Ángel Recasens).

5 Poesía cancioneril castellana, ed. Michael Gerli, Madrid, Ediciones Akal, 1994, págs. 204-08.

6 Luis de Góngora, Romances, ed. Antonio Carreño, Madrid, Ediciones Cátedra, 2000, págs. 590-92.
} 
- Pista 11. "Árboles, yerbas y plantas"

Quijote (I, 26)

Música de Mateo Romero (maestro Capitán). Cancionero de Claudio de la Sablonara (ca. 1625)

- Pista 12. "Sancho Panza es aqueste»

Quijote (I, 52)

Música de Chacón. Cancionero Musical de la Casa de Medinaceli (ca. 1550)

- Pista 14. «Suelen las fuerzas de amor»

Quijote (II, 46)

Música anónima. Cancionero Poético-Musical Hispánico de Lisboa (principios del siglo XVII)

- Pista 15. "Amor, cuando yo pienso»

Quijote (II, 68)

Música de Joan Pau Pujol (ca. 1610)

- Pista 16. "Yace aquí el hidalgo fuerte

Quijote (II, 74)

Música de Joan Pau Pujol (ca. 1610)

Sólo dos de todas estas composiciones están referidas expresamente a un contexto cantado, en el que Cervantes hace cantar a don Quijote. Son las obras «Suelen las fuerzas de amor» (II, 46) y "Amor, cuando yo pienso" (II, 68). Recordemos brevemente los respectivos pasajes de El Quijote:

Hecho esto y llegadas las once horas de la noche, halló don Quijote una vihuela en su aposento. Templóla, abrió la reja y sintió que andaba gente en el jardín; y habiendo recorrido los trastes de la vihuela y afinádola lo mejor que supo, escupió y remondóse el pecho, y luego, con una voz ronquilla aunque entonada, cantó el siguiente romance, que él mismo aquel día había compuesto:

-Suelen las fuerzas de amor

$[\ldots]$

Don Quijote, arrimado a un tronco de una haya, o de un alcornoque (que Cide Hamete Benengeli no distingue el árbol que era), al son de sus mesmos suspiros cantó de esta suerte:

-Amor, cuando yo pienso

$[\ldots]$

El resto de composiciones que hemos incluido en el CD no pertenecen a ningún contexto cantado de la novela. Las hemos incluido con la intención ya referida anteriormente de realizar una recreación poético-musical de El Quijote.

Convendría ahora a nuestro propósito tratar de las poesías escritas por Cervantes y su relación con aquellas músicas que nosotros les hemos buscado y adaptado, ya que los compositores de la época no musicaron los poemas cervantinos. ${ }^{7}$ Estas poesías diseminadas en la novela tienen un carácter incidental, puesto que ilustrar una situación determinada, ofrecen una introspección lírica dentro de un pasaje o actúan como intercalaciones poéticas que dinamizan, varían y amenizan el desarrollo de la acción. Pero, por razones de espacio, no podemos tratar de todas ellas; lo

\footnotetext{
Al respecto dice Antonio Gallego: «Un dato, por último, que puede ayudar a reafirmar la escasa atención de Cervantes por la música culta de su tiempo y, por tanto, la poca colaboración con los compositores contemporáneos es la nula atención que éstos presentaron a los versos del propio Cervantes para ponerlos en músicam. Antonio Gallego, Música en la obra de Cervantes, Madrid, Ministerio de Educación y Ciencia, 1990, pág. 6 (CD dirigido por Miguel Ángel Tallante). Por su parte, Pastor (2005), pág. 8, añade: «En Cervantes no conocemos musicalizaciones directas de sus propios textos [...]. Aunque existen noticias de que la oda "Dulce esperanza mía" (DQ I, XLIII) había sido puesta en música por Salvador Luis, cantor de capilla y cámara de Felipe II mucho antes de su publicación en la novela, hacia 1591, no hay, sin embargo, testimonio musical alguno. La composición más temprana sobre uno de sus textos procede del XVIII, precisamente sobre "Dulce esperanza mía" y aparece en el fol. $17 \mathrm{v}$., no II de un cuadernos manuscrito depositado en la Biblioteca Nacional».
} 
haremos sólo de una. Nos hemos decidido a buscarle música a los versos que Cervantes escribió para ilustrar «las finezas que de enamorado hizo don Quijote en Sierra Morena" (I, 26). En efecto nuestro hidalgo, en su retiro voluntario, «se entretenía paseándose por el pradecillo, escribiendo y grabando por las cortezas de los árboles y por la menuda arena muchos versos, todos acomodados a su tristeza, y, algunos, en alabanza de Dulcinea» (I, 26). Estos versos conforman tres estrofas de las que transcribimos la primera de ellas:

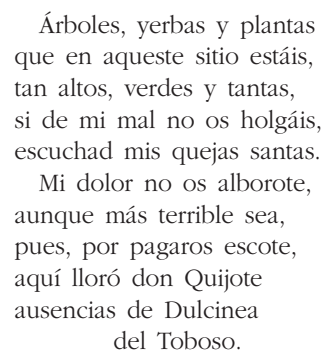

Podemos observar que estos versos forman unas estrofas llamadas quintillas. Para nuestro propósito las agrupamos de dos en dos como si fueran décimas (con todo el respeto por la preceptiva, evidentemente). La muletilla «del Toboso» es como una especie de estrambote. Y estrambótico es algo estrafalario. Con ella Cervantes nos aboca a la risa, puesto que este añadido ni rima ni encaja en la estructura estrófica. Por eso el escritor justifica la inclusión de la coletilla de este manera: "No causó poca risa en los que hallaron los versos referidos el añadidura "del Toboso" al nombre de Dulcinea, porque imaginaron que debió de imaginar don Quijote que si en nombrando a Dulcinea no decía también "del Toboso", no se podría entender la copla». En la locura caballeresca de don Quijote todo personaje elevado debía de añadir a su nombre el de su reino o patria, y así lo hace irónicamente Cervantes, quien rompe la preceptiva de la forma estrófica para respetar la enajenación de su personaje.

Y puesto que nuestro ilustre literato nos invita de continuo a la risa, a la ironía y al juego, y puesto que don Quijote se está quejando de las ausencias de Dulcinea, bien será que nosotros, tomándonos en serio la risa cervantina, acomodemos a estos versos la música de la célebre canción de las quejas y observemos, de paso, la interrelación entre lo culto y lo popular, así como la cita intertextual poética y musical. Ya tuvimos oportunidad de hablar de otros aspectos de esta canción en el XV Congreso de la Asociación Internacional de Hispanistas y en el VI Congreso de la Sociedad Española de Musicología, a cuyas actas remitimos al lector. ${ }^{8}$

La tradicional "canción que se llama Las quexas» fue recolectada por el teórico musical Francisco Salinas, quien la incluyó, junto con otras canciones populares, en su tratado De musica libri septem, publicado en 1577, con intención de ejemplificar sus teorías métricas. ${ }^{9}$ Esta tonada popular tiene un ámbito de una octava y presenta unos giros melódicos de evidente sabor tradicional.

Margit Frenk recoge en su Corpus esta cancioncilla tradicional relacionando las fuentes correspondientes: $:^{10}$

8 Mariano Lambea, "Música para textos poéticos de la Edad de Oro. Entre la tradición y la modernidad", en Actas del XV Congreso de la Sociedad Internacional de Hispanistas (Monterrey, 2004) (en prensa); y Mariano Lambea y Lola Josa, "La traza con que "hará la música milagros": un tono del maestro Capitán para unas décimas de Lope de Vega", en Actas del VI Congreso de la Sociedad Española de Musicología (Oviedo, 2004) (en prensa).

9 Francisco Salinas, De Musica, ed. Macario Santiago Kastner, Bärenreiter Verlag, Kassel und Basel, 1968, pág. 326. Existe edición española: Francisco Salinas, Siete libros sobre la música, primera versión castellana por Ismael Fernández de la Cuesta, Madrid, Editorial Alpuerto, 1983, pág. 568.

10 Margit Frenk, Nuevo corpus de la antigua lírica popular bispánica (siglos XV a XVII), México, UNAM, 2003, vol. I, págs. 287-89. 


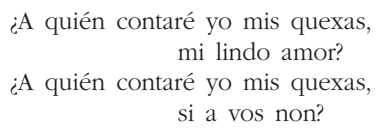

Por otra parte, Lope de Vega dejó escrito, en su poema preceptista Arte nuevo de hacer comedias en este tiempo (1609), que "las décimas son buenas para quejas». ${ }^{11}$ Con anterioridad, en la novela pastoril Arcadia (1598), el poeta ya había puesto en práctica la observancia contenida en ese endecasílabo y había incluido cinco décimas en boca del pastor Olimpio para que contara y cantara su mal. Transcribimos la primera de ellas: ${ }^{12}$

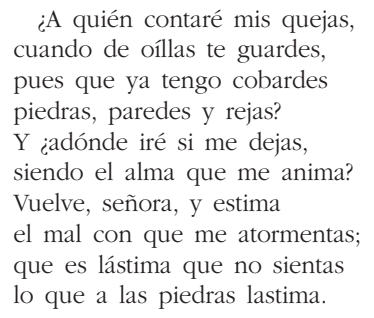

Como bien señala Morby, estas décimas «vienen a ser una especie de glosa de un verso inicial antiguo y ya popular en días de Lope». ${ }^{13} \mathrm{O}$ sea, que lo que el Fénix hizo fue recurrir al acervo popular, al inicio de un cantarcillo conocido por todos, para glosarlo líricamente e insertarlo en un marco pastoril como es la Arcadia.

Tratemos ahora del comportamiento de la música. En primer lugar cabe preguntarse qué melodía cantaría Olimpio en la ficción literaria, o mejor dicho, qué música vendría, quizá de manera inconsciente, a la mente de Lope cuando hizo que el pastor cantara sus quejas. Sin duda, la que conocían todos, la que Salinas fijó en su tratado como canción quejosa por antonomasia, aquella que el propio tratadista calificaba de «tan conocida música».

Décadas más tarde, el compositor y maestro de capilla Mateo Romero puso música a las décimas de Lope, e hizo servir idéntica estrategia compositiva que el Fénix, es decir, recurrió al venero popular. Tomó, pues, de la música tradicional, su arranque melódico, para después glosarlo armónica y contrapuntísticamente, e incluir la pieza completa a dos voces en un cancionero poético-musical de repertorio cortesano perteneciente al primer cuarto del siglo XVII, como es el Cancionero de la Sablonara.$^{14}$ Mateo Romero citó las cuatro primeras notas de la melodía recogida por Salinas; ciertamente un motivo musical breve, pero suficiente para la referencia musical intertextual, para el reconocimiento de la tonada popular por parte del auditorio de la época.

Nosotros hemos tomado la música que el maestro Capitán compuso para las décimas «iA quién contaré mis quejas?» y la hemos adaptado a cada grupo de dos quintillas, con lo cual no hemos tenido ninguna dificultad métrica. La muletilla cervantina se adapta perfectamente a la música de Capitán, puesto que el compositor repitió la última palabra de cada décima. El argumento es similar en ambos casos.

Por nuestra parte no podíamos dejar pasar la oportunidad de homenajear a Cervantes en este IV Centenario, cantando sus propios poemas con las músicas que, sin duda, a él le hubiera gustado escuchar. Nos congratula creer que hacemos un acto de justicia poética y no podemos, ni queremos, detener el vuelo de nuestra imaginación al pensar que el genial escritor quizá podría tener

11 Lope de Vega, El arte nuevo de hacer comedias en este tiempo, ed. Juana de José Prades, Madrid, CSIC, 1971, pág. 297. Para más datos sobre este endecasílabo véanse las págs. 193-97.

12 Lope de Vega, Arcadia, ed. Edwin S. Morby, Madrid, Editorial Castalia, 1975, págs. 185-87.

13 Morby (1975), pág. 185, n. 112.

${ }_{14}$ El Cancionero de la Sablonara, ed. Judith Etzion, London, Tamesis Books, 1996. 
en la memoria e, incluso, tararear estas melodías mientras escribía su obra maestra. Con nuestra aportación hemos conseguido también -y aunque esto sea pura anécdota, si se quiere ver como tal- que los nombres de los personajes de la ficción cervantina, como el propio don Quijote, Alonso Quijano, Dulcinea o Sancho Panza, figuren puestos en música, así como los lugares de La Mancha o del Toboso.

Con la audición de estas poesías pretendemos volver a la inversa, si se nos permite, el atinado razonamiento de la profesora García de Enterría, cuando expone que «los oyentes de entonces que recibían de modo performativo estos textos poético-musicales se han transformado en lectores -nosotros- la mayor parte de las veces». ${ }^{15}$ Pues bien, con la aportación de la musicología, sobre todo, si trabaja interdisciplinariamente con la filología, se puede conseguir que nosotros, lectores de hoy, volvamos a ser, "de modo performativo", oyentes de ayer. Éste es uno de los grandes retos que tiene actualmente la musicología española.

15 García de Enterría (1997), pág. 170. 